\title{
Energy labelling at point-of-choice in catering establishments
}

\author{
C. Sadler and W. Wrieden \\ Robert Gordon University, School of Pharmacy and Life Sciences, St Andrew Street, Aberdeen AB25 1HG, Scotland, UK
}

The provision of energy information for menu items, at the point they are ordered, in chain restaurants has been mandated across the $\mathrm{US}^{(1)}$. Current policy in the UK is encouraging a voluntary scheme. This is intended to be a 'first step' to 'provide consumers with clear and simple information that will enable them to make informed choices and identify foods that help them to meet their energy needs, and enable them to better maintain energy balance and a healthy weight ${ }^{(2)}$. There is little evaluation of energy labelling and controversy over whether it is wanted or needed. Mintel said only $16 \%$ want to see energy information ${ }^{(3)} v .40 \%$ reported by a UK postal survey ${ }^{(4)}$. IGD ${ }^{(5)}$ reported that just under half did not appear to consider balancing energy intake with expenditure. It has been reported that consumers understand the concept of energy, but closely link it to weight-loss, rather than healthy weight, and can overestimate the energy used during exercise ${ }^{(6)}$.

This study aimed to gauge consumers' perceptions of energy information. Dining consumers ( $n$ 92; 60\% female) were surveyed in Aberdeen; the main sample in a central food-court was combined with the initial sample ( $n$ 16) from a casual dining restaurant. The questionnaire, based on the theory of planned behaviour ${ }^{(7)}$, explored intention to use the information for managing their weight. The survey included an example menu including energy information. Participants were questioned about using energy information to choose lower energy from the menu, determine wider diet or for physical activity.

Evaluations were positive; $49.5 \%$ thought energy information is very helpful, and the majority would use it for managing their weight $(P<0.001)$. Attitudes towards choosing lower energy from the menu (about $65 \%$ positive), and the rest of the $\mathrm{d} /$ week $($ about $64 \%$ positive) were related to intention $(r=0.417, r=0.403$, respectively, $P<0.01)$. Half believed avoiding weight gain is very important; this also related to intention $(r=0.381, P<0.01)$. Less than half thought using energy information would be easy, approximately $30 \%$ thought it would be difficult. Again the majority said choosing to expend energy by being physically active is good (73\%), and that it was neither difficult nor easy $(30 \%)$ or quite easy $(34 \%)$.

There was wide variation in estimates of how long it would take walking ( $3 \mathrm{mph}$ ) to burn 100 Calorie; which ranged from 4 to $120 \mathrm{~min}$. Overall the mean was 30.62 (SD 22.41) min. This suggests individuals are not knowledgeable about energy used in physical activity, which agrees with other research ${ }^{(6,8)}$.

The results suggest that consumers think energy information is helpful and they intend to use it. Actual use depends on contextual factors involved in food choice. Caterers should make choosing lower-energy options easier. A process evaluation of the energy labelling scheme trial ${ }^{(5)}$ concluded that its usability is dependent on visibility, understanding and engagement. Understanding of energy balance is needed for people to have a realistic view of energy use.

1. CSPI (Center for Science in the Public Interest) (2010) Health reform to deliver calorie counts to chain restaurant menus nationwide. Washington, DC:CSPI. http://www.cspinet.org/new/201003211.html

2. Food Standards Agency (FSA) (2009) Food Standards Agency Consultation. Provision of calorie labelling at point of choice in catering outlets. London: FSA. http://www.food.gov.uk/multimedia/pdfs/consultation/calorielabellingcateroutlets.pdf

3. MINTEL (2009) Eating out meal occasions - UK - October 2009. http://academic.mintel.com

4. Mackison D, Wrieden WL \& Anderson AS (2009) J Hum Nutr Diet 22, 567-573.

5. IGD (Institute Of Grocery Distribution) (2009) Working group report. Portion size: understanding the consumer perspective. Watford: IGD. http:// www.igd.com/index.asp?id=1\&fid=1\&sid=4\&tid=54\&cid=1052

6. Clegg S, Jordan E \& Slade Z (2009) An evaluation of provision of calorie information by catering outlets. London: FSA. http://www.food.gov.uk/ multimedia/pdfs/publication/evalcalinfocateringoutlets.pdf

7. Francis JJ et al. (2004) Constructing questionnaires based on the theory of planned behaviour. A manual for health services researchers. Newcastle upon Tyne: ReBEQI. http://www.rebeqi.org/ViewFile.aspx?itemID=212

8. EUFIC (European Food Information Council) (2009) Nutrition information on food labels - is it read and understood? http://www.eufic.org/article/en/ health-and-lifestyle/food-choice/artid/Nutrition-information-food-labels-read-understood/ 